\title{
Learner Perceptions of Chinese EFL College Classroom Environments
}

\author{
Hui Peng ${ }^{1}$ \\ ${ }^{1}$ College of Humanities and Social Sciences, National University of Defense Technology, Changsha, China \\ Correspondence: Hui Peng, College of Humanities and Social Sciences, National University of Defense \\ Technology, Changsha, Hunan, 410074, China. E-mail: phs2013@126.com
}

Received: September 2, 2015 Accepted: November 28, 2015 Online Published: December 1, 2015

doi:10.5539/elt.v9n1p22

URL: http://dx.doi.org/10.5539/elt.v9n1p22

\begin{abstract}
This study, carried out at a major technological university in China and based on a convenience sample of 116 students, is designed to identify which aspects of their classroom environments had the greatest effect on the students. Students completed a 26-item questionnaire which elicited general as well as specific views on the EFL classroom environments. The students were divided into English majors $(\mathrm{n}=64)$ and non-English majors $(\mathrm{n}=52)$. The results showed that, among the items rated as less satisfactory, eight items were similar for both groups, but that the items with lowest satisfaction for each group were significantly different. For English majors textbook selection, learning atmosphere, and teachers' chalkboard presentation are least satisfactory; for non-English majors interest in target culture, teachers' chalkboard presentation, and internal motivation are the least satisfactory. The paper concludes that English-language education should be treated differently for majors and non-majors. For English majors, to improve the learning atmosphere, textbook selection and teaching methods need be considered as priorities. English-language education for non-majors should be redesigned with a focus on functional use of the language rather than in-depth study of the target culture.
\end{abstract}

Keywords: EFL learners, classroom environments, ecological perspective

\section{Introduction}

With the gradual reform of university English teaching in China towards a focus on communicative competence and students' actual use of the language, attempts have also been made to improve the quality of the classroom environment. This is in line with recent thinking about the ecology of the classroom experience and how this can offer affordances and constraints around successful language teaching.

As Williams and Burden (1997) have noted, the condition of classrooms affects learning on all levels. At the most basic level, the physical and interpersonal environments of a classroom critically impact the language learning that takes place for individual students. At the broadest level, the language classroom is affected by national and cultural conditions, and then by the nature of the educational system within the country. In other words, for a variety of intertwined factors, research on the EFL classroom cannot be restricted to applied linguistics. Broadening horizons in EFL classroom research from multidisciplinary perspectives, as well as observing the classroom environment from an ecological perspective, have become more common in recent years.

\subsection{Ecology of Education}

As Bronfenbrenner (1976) has pointed out, when discussing whether and how people learn in educational settings, there are two sets of relations: one between the characteristics of learners and their surroundings, and the other the relations and interconnections that exist between the components of these environments. "The scientific study of both sets of relations as they affect learning constitutes the ecology of education" (Bronfenbrenner, 1976, p. 5).

\subsection{An Ecological Understanding of EFL Classrooms}

An ecological understanding of classrooms emerged in the late 1960s (Doyle, 2006, p. 98). In his review of research on teacher effectiveness, Doyle (1977) identifies three paradigms. The first is the "process-product paradigm" emphasizing teacher variables as factors directly affecting student learning outcomes. The second is the "mediating process paradigm" stressing student response variables as factors affecting learning outcomes. The third is the "classroom ecology paradigm" highlighting "mutual relations among environmental demands 
and human responses in natural classroom settings". The first and second paradigms attribute student learning outcomes primarily to two factors, teacher or student behavior. But teacher variables, student variables, and the classroom settings are all factors that affect learning outcomes, so we need to think about "complexities within a single classroom environment" (Doyle, 1977, p. 178).

In recent years, preliminary studies from an ecological perspective on classroom teaching have begun to appear in China. For example, the Chinese discussion of the classroom ecological environment was initiated with Fan's (2000) Educational Ecology, which draws special attention to the classroom ecological environment. In 2007, the Ministry of Education in China released a new edition of College English Curriculum Requirements which has played an important role in promoting college English teaching reform. It shows clearly that factors such as teachers, learners, teaching media and teaching content together constitute a classroom ecosystem which can influence and expand students" "willingness to communicate (WTC)" and perhaps eventually have the greatest impact on EFL success in China (Peng, 2012).

To produce positive outcomes for learners, optimizing the classroom environment becomes crucial. Teachers, students, and the classroom environment make up the whole classroom ecosystem. The three parts are relatively independent, but also interrelated, and thus interactive.

This paper is concerned with Chinese EFL college students and their situation from four dimensions: (a) physical environment, including lighting, equipment, classroom size, and seating arrangements; (b) teaching environment, including teacher-student relationships, class size, classroom activities, teacher-student interaction, student-centeredness, teaching methods, and teachers' modes of presentation; (c) learning environment, including enthusiasm for learning, autonomous learning, ability to use English, learning atmosphere, and textbook selection; and (d) motivational environment, including willingness to participate, willingness to learn, attitudes towards tests/exams, interest in English, interest in target culture, purpose to study, and motivation. This paper examines the EFL classroom environment in a technological university where all students are required to take courses in English. I examine student perceptions of the classroom in order to analyse students' perceived affordances and constraints in the English classroom environment and consider the parameters of more effective English teaching in Chinese technological universities.

\section{The Study}

\subsection{Context}

The study was conducted at a major technological university in China. Participants were a convenience sample of 116 freshmen, sophomores, juniors, and seniors (male $=97$; female $=19)$ taught by 15 non-native teachers. They included 64 English majors (EM) and 52 non-English majors (NEM) from 19 EFL classes. In their first or/and second academic years, as nationally prescribed, English majors should take four basic English courses, listening, speaking, reading, and writing; non-English majors should take two basic English courses: listening and speaking, reading and writing; the textbook and the content of the courses are not nationally prescribed. The students came from different places in China.

\subsection{Research Design}

In order to examine the environment perceptions of the participants, a questionnaire was developed in terms of four research dimensions: physical, teaching, learning, and motivational. These dimensions evolved from Pielstick's (1988) assessment instrument which identifies the four aspects of learning environment as physical, social, instructional, and psychological. The questionnaire contained 26 Likert-scaled statements representing the four dimensions, two multiple-choice questions asking for preferences for seating arrangements and classroom activities, and one open-ended question asking about preferences for class size. Each statement item had five levels: Level 1 = strongly disagree, Level 2 = disagree, Level $3=$ neither agree nor disagree, Level $4=$ agree, and Level 5 = strongly agree. In the final data extraction, satisfaction (Levels 4 and 5) was the focus. Data were collected separately for English majors and non-English majors. Interviews were conducted with among 30 selected juniors and seniors, including 15 English majors and 15 non-English majors.

\subsection{Research Questions}

The research questions addressed are as follows:

1) What are the perceived satisfactions of Chinese students with the current physical, teaching, learning, and motivational dimensions in their EFL classroom environments?

2) Are there any differences in perceptions between English majors and non-English majors? 


\section{Results}

\subsection{The Physical Dimension}

Table 1 presents the findings on four aspects of the physical environment: lighting, equipment, classroom size, and seating arrangements. As seen in Table 1, both English majors and non-English majors are satisfied with the lighting of the English classroom. The science students' satisfaction with the equipment is much lower than the English majors; eighty-three percent of the English majors and 67 percent of the non-majors perceive the teaching equipment as meeting the needs of English classroom teaching.

Table 1. Physical dimension

\begin{tabular}{lll}
\hline & \multicolumn{2}{l}{ Satisfaction (\%) } \\
\cline { 2 - 3 } Item & EM & NEM \\
\hline 1. My English classroom is well lit. & 90.6 & 92.3 \\
2. The equipment in my classroom is advanced, able to meet the needs of English language & 82.8 & 67.3 \\
teaching. & & \\
3. The size of the classroom is conducive to teaching activities. & 70.3 & 63.5 \\
4. I'm satisfied with the seating arrangements in my English classroom. & 59.4 & 53.8 \\
\hline
\end{tabular}

On the other hand, only half of the students are satisfied with the seating arrangements in their classrooms. When answering the question "Which kind of seating arrangements do you prefer?" (multiple choice according to Harmer's (2000) four categories: orderly rows, circles, horseshoes, and separate tables), 43 percent of students indicate a preference for "separate tables," 30 percent for "horseshoes," and 21 percent "circles". Only 5 percent of the students prefer "orderly rows," which is the current seating arrangement in most English classrooms in China.

\subsection{The Teaching Dimension}

Table 2 presents the findings on students' perspectives on different aspects of the teaching environment. As seen in Table 2, both groups of students indicate considerable satisfaction on all items except for those on teaching methods and teachers' modes of presentation. Forty-eight percent of the English majors and 67 percent of the non-English majors are satisfied with their classes' English teaching methods. Forty-two percent of the English majors and 37 percent of the non-English majors favor greater chalkboard use by teachers; 61 percent of the English majors and 52 percent of the non-English majors prefer greater use of PowerPoint presentations, multimedia courseware, and multimedia devices. In the main, the non-English majors are consistently more satisfied with aspects of the teaching environment, such as student-centeredness and classroom activities than are the English majors.

Table 2. Teaching dimension

\begin{tabular}{lll}
\hline & \multicolumn{2}{c}{ Satisfaction (\%) } \\
\cline { 2 - 3 } Item & EM & NEM \\
\hline 5. The relationship between the teacher and me is equal, friendly and harmonious. & 98.4 & 100.0 \\
6. Teachers treat me with respect and patience. & 93.8 & 88.5 \\
7. I'm satisfied with class size. & 84.4 & 76.9 \\
8. My teacher can effectively schedule and organize classroom activities. & 67.2 & 80.8 \\
9. There's frequent interaction between the teacher and me. & 60.9 & 69.4 \\
10. The concept of student-centeredness is fully reflected in my English class. & 54.7 & 71.2 \\
11. I'm satisfied with the current teaching methods. & 48.4 & 67.3 \\
12. I prefer greater use of PPT and multimedia devices by teachers. & 60.9 & 51.9 \\
13. I prefer greater use of chalkboard presentation by teachers. & 42.2 & 36.5 \\
\hline
\end{tabular}


Of all the items of the questionnaire, the one with the highest degree of satisfaction is with the teacher-student relationship. Ninety-eight percent of the English majors and 100 percent of the non-English majors think that the relationship between teachers and students is equal, friendly and harmonious; 94 percent of the English majors and 89 percent of the non-English majors consider that teachers treat students with enough patience. However, only 61 percent of English majors and 69 percent of non-majors think the frequency of the interaction between teachers and students is enough.

As for classroom activities, the majority of students (67 percent English majors; 81 percent non-English majors) perceive that their teachers can effectively organize classroom activities. When answering the question "Which kind of classroom activities do you prefer?" (multiple choice), their preferences are "group work" (37 percent), "debate" (25 percent), "whole class" (15 percent), "pair work" (12 percent), and "solo work" (11 percent).

Both English majors and non-English majors are satisfied with their current class size, but they have different preferences. When answering the open-ended question "How many students in a class do you prefer?", most English majors think an ideal class size is 10-15 learners, while non-majors prefer 20-30 learners.

Overall, these students perceive the relationship between teachers and students and classroom activities as satisfactory, especially the teacher-student relationship.

\subsection{The Learning Dimension}

Table 3 presents the findings on students' perceptions of different aspects of the learning environment. As seen in Table 3, there is a clear pattern of differences between the English majors and non-English majors, with non-majors' satisfaction generally higher than majors. As a whole, they are relatively dissatisfied with the learning dimension when compared to the physical and teaching dimensions.

Table 3. Learning dimension

\begin{tabular}{lll}
\hline & Satisfaction (\%) \\
\cline { 2 - 3 } Item & EM & NEM \\
\hline $\begin{array}{l}\text { 14. The teacher uses some innovative teaching methods to increase my enthusiasm for } \\
\text { learning English. }\end{array}$ & 54.7 & 69.2 \\
$\begin{array}{l}\text { 15. My ability to use English has been greatly improved through various classroom } \\
\text { activities. }\end{array}$ & 53.1 & 63.5 \\
$\begin{array}{l}\text { 16. With their moderate difficulty level, my English textbooks help raise the level of my } \\
\text { English proficiency. }\end{array}$ & 50.0 & 59.6 \\
17. There's a strong English learning atmosphere in my class. & 37.5 & 51.9 \\
$\begin{array}{l}\text { 18. I've gotten used to the autonomous learning mode, which helps me consciously manage } \\
\text { independent learning. }\end{array}$ & 43.8 & 42.3 \\
$\begin{array}{l}\text { 19. English textbooks are relatively new and consistent with my English learning habits; } \\
\text { they meet my English learning needs. }\end{array}$ & 26.6 & 51.9 \\
\hline
\end{tabular}

The findings show that both groups of students are dissatisfied with currently used textbooks, with the English majors' level of satisfaction as low as 27 percent. However, 50 percent of English majors and 60 percent of non-English majors perceive that existing English textbooks are appropriate in terms of difficulty.

With regard to the learning atmosphere, the satisfaction ratings are low for both groups of students, especially for English majors. Only 38 percent of the English majors express satisfaction. Only 53 percent of the English students and 64 percent of the non-English students perceive improvement in their English ability through English classroom activities.

\subsection{The Motivation Dimension}

Table 4 presents the findings on the students' perspectives on different aspects of the motivational environment. Students are all relatively satisfied with the motivational dimension when compared levels of their responses to the learning dimension. 
Table 4. Motivational dimension

\begin{tabular}{lll}
\hline & \multicolumn{2}{l}{ Satisfaction (\%) } \\
\cline { 2 - 3 } Item & EM & NEM \\
\hline 20. I'm willing to actively participate in classroom activities. & 76.6 & 82.7 \\
21. I'm willing to learn English in the classroom. & 75.0 & 82.7 \\
22. Considerable pressure coming from TEM 4 and TEM 8 (or CET 4 and CET 6) motivates & 67.2 & 73.1 \\
me to study English hard. & & \\
23. I'm very interested in English. & 53.1 & 55.8 \\
24. I know very well why I'm studying English, which gives me a strong sense of purpose to & 50.0 & 50.0 \\
learn the foreign language. & & \\
25. I have internal motivation to learn English. & 48.4 & 40.4 \\
26. I'm interested in the target culture as well as the target language. & 46.9 & 28.8 \\
\hline
\end{tabular}

As seen in Table 4, both groups' responses are similar except for the item on interest in the target culture: 47 percent and 29 percent for English majors and non-English majors respectively. The results show that both groups of students lack curiosity about the cultural basis of the language, with the non-English majors' level of interest as low as 29 percent. They see tests positively. Although they feel under pressure, they think the pressure of tests (including CET4, CET6, TEM4, TEM8, and final exams) stimulates them to further efforts in learning English.

The story, accordingly, goes like this: they are all willing to learn English, and they feel pressured to learn English; they are willing to participate in classroom activities, but they are not interested in either English or the cultural context of English.

\section{Affordances and Constraints in the Four Dimensions}

\subsection{The Physical Dimension}

Overall, the findings of the survey suggest that the classrooms at this university facilitate teaching and learning, but the seating arrangements are a problem. Most of the chairs and tables cannot be moved. This affects the way students can learn and the way teachers can teach.

The issue is the seating arrangement of "orderly rows". The horizontal-vertical row model is a widely used seating arrangement in Chinese classrooms. In this kind of arrangement all the students are facing and working with the teacher, and the teacher is the authority, which conforms exactly to the traditional Chinese culture. The teacher is a controller and assessor.

There are reasons, of course, why the use of orderly rows is less satisfactory and does not fit into today's thinking that the role of the teacher is as a facilitator. First, learners in orderly rows get little chance to speak the target language because the teacher, like a controller, dominates the class. Moreover, there is little opportunity for students to communicate with each other. In interviews, students observed that the use of a non-movable seating arrangement hinders exchanges and discussions among students. It, accordingly, restricts classroom activities and cooperative learning (see Nunan, 2001, p. 83).

\subsection{The Teaching Dimension}

The major issue that lies in the teaching dimension is the types of activities. Most students clearly stated that they prefer the kind of activities like "group discussion" and "class debate". Why might most students favor "group discussion" and "class debate"? First, such activities provide more chances for communication. These activities provide learners with good opportunities for interaction, such as information exchange and negotiation of meaning. Thus, they provide a good classroom environment for the implementation of task-based language teaching. The results show that group discussion and classroom debate can be promoted in EFL classrooms. However, in doing so, teachers should pay attention to balancing whole-class, individual, pair, and group learning (Kinsella, 1995).

The second issue that lies in the teaching dimension is the teachers' modes of presentation. The results show that students' preferences for teachers' presentation are varied by major, with science students' higher expectations of teachers' technology-relevant modes of presentation being obvious. In an era of highly developed information 
technology, both chalk-and-talk-only and PowerPoint-only presentations are unable to meet the needs of learners. Language teachers can explore more integrated modes of classroom presentation which are in accord with the characteristics of learners' habits, and at the same time use new technology.

Using communicative activities and multimodal means of presentations to enhance classroom interaction plays a crucial role for mobilizing the enthusiasm of learners, enlivening the atmosphere of the classroom, and improving learning outcomes. In the educational ecosystem, teachers and students are the two key situational factors, and the harmony and interaction between them are important for the successful development of classroom teaching.

\subsection{The Learning Dimension}

The major issue that lies in the learning dimension is the textbook. Both English majors and non-English majors indicate low satisfaction with their currently used textbooks. Some of the textbooks are dated and from the dynamic view of ecology in an era of rapid updating of knowledge, language textbooks should reflect this change.

Another reason is that many of the reading textbooks focus too much on separate skills rather than the integration of different skills. Many EFL learners are not good at writing. Textbooks should address student's deficits in writing, and emphasize the writing process and critical thinking. Reading sets a good example for writing (Harmer, 2000). Textbook compilers should put contemporary language-acquisition theory into practice, along with a wide range of motivating activities that reinforce effective writing. Separate treatment of the four skills of listening, speaking, reading and writing is necessary for lower-level learners, but for university students, especially for those who have completed freshman level coursework, special emphasis should be put on the integration of the four skills.

The survey findings suggest the learners' preferences for a more active learning environment. Choosing suitable textbooks to engage students in the process of active learning becomes more and more important in EFL teaching. American-based ESL courses that integrate reading and writing in academic programs may be a good example to follow (see Dollahite \& Haun, 2012 for a textbook example).

\subsection{The Motivation Dimension}

The survey results show that both English majors and non-English majors claim a relatively low level of interest in both the language and the target culture. These results suggest two crucial issues in Chinese EFL education. The first issue is the importance of developing students' intrinsic motivation in learning. Most students do not think of themselves as highly intrinsically motivated, they take required courses that have tests associated with them. In China, English language-teaching curricula at the university level are normally divided into two branches: undergraduates whose majors are not English (non-English majors) and those whose majors are English (English majors). Both groups of undergraduates are required to take national standardized English tests before graduation. Non-English majors take CET 4 and CET 6, and English majors take TEM 4 and TEM 8.

Motivation plays an important role in language learning, and motivation also needs to be actively nurtured in teaching practice (Dornyei, 2014; Wu, 2003). However, the problem is how to transform extrinsic motivations into intrinsic motivations. Brown (2007) has pointed out that the consequence of extrinsic motivations is teaching students to play the "game" of pleasing teachers rather than developing students' internalized thirst for knowledge. Brown (2007) encourages turning extrinsic elements "in an intrinsically oriented direction". Brown's notion is that an intrinsically oriented school can "transform itself into a more positive, affirming environment" (pp. 90-91).

The second issue is the treatment of culture in Chinese EFL education. The target-culture item raises interesting questions about why students are not interested in learning about the target culture. The motivation items (see Table 4) show that they want to be able to use the language, but they do not express an interest in learning about the target culture. This is in line with Hinkel's (2014) contention that learners who study in English-speaking communities "have a much greater need for developing their cultural competencies than those who study EFL as a part of their foreign language requirements" (pp. 396-397). Weger's (2013) study found that "even in a study abroad setting, international English learners are less motivated by positive attitudes toward the English community".

Why are students not interested in learning about the target culture? The answer to this question has to do with the existence of two kinds of goals. One is the learner's goal, the other is the educational or institutional goal. "The learners' actual goals in attaining English proficiency may serve as guidelines for determining their needs in learning culture", while the educational goal is "to enable learners to become successful in an international 
community, in the global economy, and across national boundaries" (Hinkel, 2014, pp. 395-397). Since students are learning in a non-English-speaking world, accordingly, it is hard for them to perceive what important role culture would play in their future career or life. What they are more interested in is functional English.

Language research has shown that an awareness of the target language's culture is important in being able to fully master the language, but students in the EFL classroom show little interest. The ecological approach to teaching recognizes the importance of incorporating students' motivation into the curriculum, and Brown (2007) has pointed out the importance of turning extrinsic motivation into intrinsic motivation. All these points add up to a recognition that the role of teaching English-language culture in the Chinese EFL classroom may need to be reconsidered. As English comes to play a different role in the Chinese undergraduate university curriculum, we may need to rethink the teaching of culture, especially to non-English majors. Thus, language teachers are faced with the challenge of finding a balance between learners' needs, learners' goals and educational/institutional goals. Teaching practice is no longer a one-way street; it becomes more a two-way strategy of integration.

\section{The Two Groups of Learners}

Bronfenbrenner (1976) has contended that the relation between the characteristics of learners and their surroundings affects learning. As we have seen, while the two groups of students have their own characteristics, what they bring to the classroom and how they interact with their surroundings are different. In order to find whether there is anything common governing the lowest satisfaction ratings for each group, I compared each group's items with satisfaction percentages below 60 percent. Both groups have eight lowest satisfaction items in common and two items that are unique to each group.

\subsection{General Pattern of Lowest Satisfaction Survey Findings}

Figure 1 provides a comparison of the ten items with the lowest satisfaction ratings (percentages below 60 percent) across the two groups of students. The comparison suggests four findings.

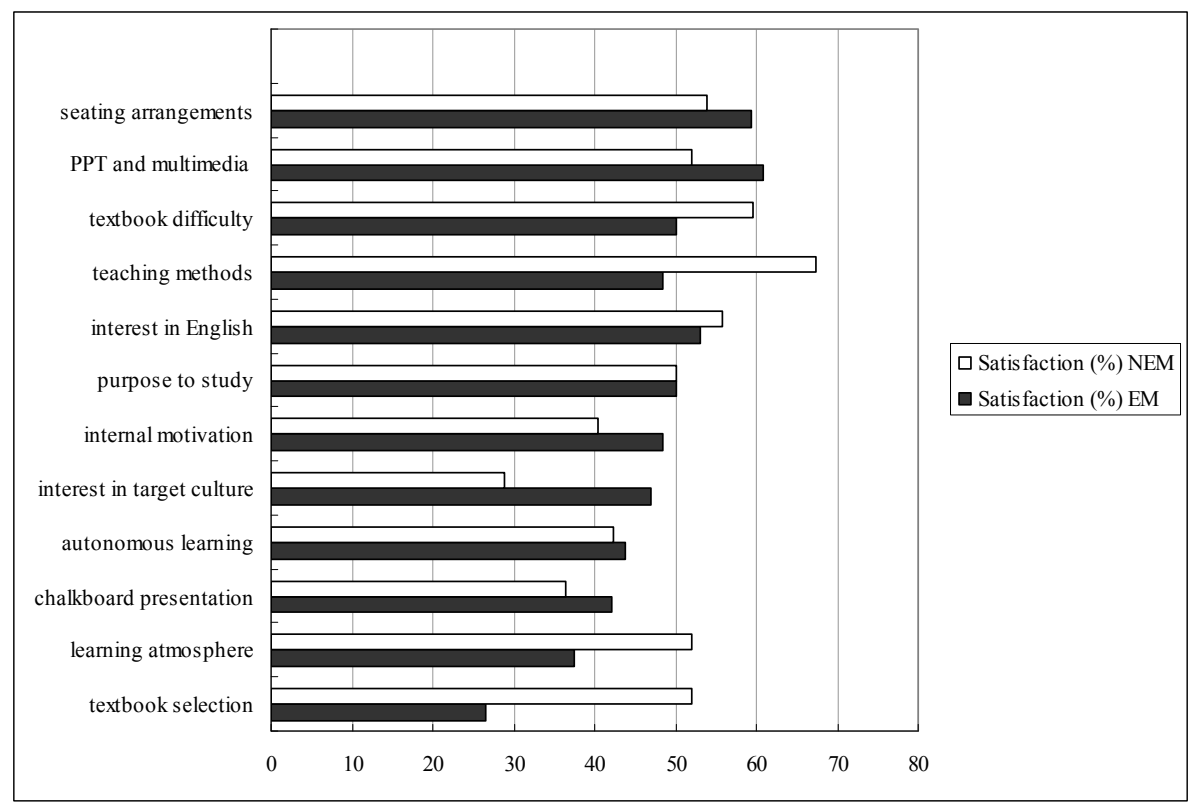

Figure 1. Comparison of differences by major in lowest satisfaction items

First, among these ten items rated as less satisfactory, eight are identical for both groups: (1) textbook selection; (2) learning atmosphere; (3) teachers' chalk-and-talk presentation; (4) autonomous learning; (5) interest in target culture; (6) internal motivation; (7) purpose to study; (8) interest in English.

These overlapping items might suggest a pattern of general relative dissatisfaction for both groups of students.

There, however, are four items to which the groups respond differently. English majors have less satisfaction than their non-major peers with (1) teaching methods and (2) textbook difficulty, while non-English majors have less satisfaction with (1) teachers' PPT and multimedia presentations and (2) seating arrangements.

Thirdly, the item of least satisfaction ( $<30$ percent) is "textbook selection" (Item 19) for English majors, and 
"interest in target culture" (Item 26) for non-English majors.

Finally, and most importantly, within the general pattern of the lowest satisfaction items, there is another pattern showing differences between the two groups. The items with the greatest differences ( $>10$ percentage points) between the two groups are: textbook selection (25 percentage points), teaching methods (19 percentage points), interest in target culture (18 percentage points), and learning atmosphere (14 percentage points). English majors are less satisfied with textbooks, teaching methods and learning atmosphere; non-majors are less satisfied with interest in target culture. The following is a discussion of the differences across the two groups.

\subsection{Discussion of the Differences across the Two Groups}

\subsubsection{Textbook Issue}

Compared with non-majors, the English majors are less satisfied with their textbooks. There exist three reasons underlying this textbook problem. First, the number of textbooks for English majors is limited, and there are only a few sets of textbooks compiled for them in the Chinese book market. In addition, textbooks for English majors often take a long time to get updated. Many English majors said, when interviewed, that they need to be exposed more to more new language materials. In an EFL context like China, a large majority of the EFL students are non-English majors. Because of this large population, textbooks for non-majors usually get updated more frequently than those for English majors.

Secondly, English majors have higher expectations for information and knowledge in English-related issues. Since they are taking English as their major, they need such textbooks that can inform them of different related disciplines, such as literature, film, drama, and music. To solve this problem, textbook compilers need to take both the real-world need and the classroom need into consideration in order to increase the fit between real-life language use and pedagogical language materials in EFL contexts.

Thirdly, English language-learners have multiple purposes in learning. If we assume that many non-majors prefer functional textbooks, and such functional textbooks can meet the needs of their future occupations as scientists and engineers, we would say their needs are to some extent pointed toward, for example, writing and presenting scientific academic papers at international conferences, and publishing papers in English-speaking academic circles. In contrast, English majors may take up different English-related occupations in the future, for example, as an EFL teacher, interpreter, translator in a scientific field, a literature field or a commercial field. Therefore, textbooks for English majors should serve their multiple purposes.

\subsubsection{Method Issue}

English majors are also less satisfied with teaching methods. Their expectations for teaching methods used in the classroom are higher than non-majors. In the interview, English majors revealed their dissatisfaction with teachers using one particular method all the time, while non-majors did not express much concern about the use of one particular method. This finding illustrates the complexity underlying language teaching.

The issue of teaching methods has had a long history in language teaching. "Methods are too prescriptive, assuming too much about a context before the context has even been identified. They are therefore overgeneralized in their potential application to practical situations" (Brown, 2002, p. 10). Classroom teaching is influenced by changes in different groups of learners, subject matter and milieu. The use of a single method is insufficient to address the complexity in teaching. Whether it is grammar-translation or task-based language teaching, every method has its own particular objectives and focuses. We are now in the post-method era (Richards \& Rodgers, 2001; Brown, 2002). The concept of "method" has undergone changes. Language teachers should be well-informed about the current approaches and techniques in teaching, and explore their own beliefs and methods in language teaching (Richards \& Rodgers, 2001). The era we are in suggests to us the importance of teacher development and a call for eclectic teaching methods.

There is a large portion of EFL learners with different majors in China. "The diversity of language learners in multiple worldwide contexts demands an eclectic blend of tasks, each tailored for a specified group of learners studying for particular purposes in geographic, social, and political contexts" (Brown, 2007, p. 41). In university language programs, teachers should respond flexibly to different contexts and use innovative ways to achieve overarching goals and specific objectives in teaching.

\subsubsection{Learning Atmosphere Issue}

With regard to the issue regarding learning atmosphere, there is a sharp difference between the two groups. The English majors' satisfaction is approximately 14 percentage points lower than the non-majors, which is in line with my observation that non-majors are more active in class. 
From what has been discussed above, a chain effect can be hypothesized among the three aspects for the English majors: textbook - teaching method-learning atmosphere. As shown in the questionnaire data, English majors are not satisfied with the textbook used in class. Since textbooks normally presume certain teaching methods, the textbooks would, to some extent, limit teachers' choices of methods. This may lead to learners' dissatisfaction with the teachers' methods. Because of this, they are not happy in class and this would ultimately affect classroom atmosphere. Consequently, they do not show much enthusiasm in doing things, such as answering the teachers' questions and interacting with peers.

Classroom management for English majors has its own peculiar characteristics. This hypothesized chain effect suggests that, for English majors, classroom atmosphere is greatly affected by textbook use and teaching methods. To improve the learning atmosphere, the interconnections of the classroom components must be taken into consideration. Thus the success of classroom learning is very much dependent on what the atmosphere is like. If students could actively participate and communicate in class, the outcome of learning would be more productive. This and previous findings further suggest that English majors want participatory methods, in addition, such methods are supported by interactive materials, seating arrangements (e.g. separate tables), and activities (e.g. group work).

\subsubsection{Culture Issue}

With the issue regarding target culture, there is a sharp difference in the two groups - the percentage difference is approximately 18 percentage points, with non-English majors' lower satisfaction being obvious. Non-English majors are all science and engineering students in this university. They have English classes twice a week. When the teacher discusses culture, they consider it a waste of time because they are not interested in it. Instead, science students are more interested in taking and passing exams and skill-based learning. ${ }^{1}$ English majors, on the other hand, have English classes every day. They get more exposure to the language and its culture, and more opportunities to study and use English. The differential teaching of cultural background knowledge and the development of sociocultural competence to different groups of students becomes an important aspect in EFL instruction.

Why are non-majors less interested in the target culture? When interviewed, many non-English majors suggested studying the target language culture will not be closely related to their future occupations. This suggests that a more science-oriented target culture, for example, the rhetoric of academic writing, might be more meaningful to science students.

\subsection{Implications of the Comparison}

Overall, the findings reveal that there are differences and also similarities in the two groups' responses to the same item. The similarities demonstrate that the two groups expect a similar classroom environment soundly grounded in principles of second-language acquisition and pedagogy. They overwhelmingly want participation in class. The sharp differences indicate that, in Chinese EFL classes, the two groups should be treated differently and there should be different curricula and syllabi, and different textbooks and materials that will be consistent with the educational goal that nurtures students in their English-language learning. Thus, it can be seen that the perceived constraints that affect the English language classroom ecological balance are different for the two different groups. Only by constantly eliminating the hindering factors, can we improve our effectiveness in the English classroom and achieve a more satisfactory ecological environment.

\section{Conclusion}

This paper focuses on the student-perceived affordances and constraints in the EFL classroom environments in one technological university in China. The study found that: (1) In general, problems focus on seating arrangements, types of activities, teachers' modes of presentation, textbook selection, and interest in the English-language culture. (2) For English majors and non-English majors, there are eight among the 10 lowest satisfaction items that are the same for both groups. (3) For English majors, there exists a chain effect among the three environmental factors: textbook, teaching method, and learning atmosphere. To improve classroom atmosphere, textbook suitability and teaching method appropriateness need be considered as priorities. "Textbook selection" is the most critical item for English majors: they are dissatisfied with using out-of-date textbooks. (4) For non-English majors, the most critical item is "target culture interest". Most of them are not interested in the target culture. They appear to be more interested in functional English rather than the culture of the target language. And as Montgomery (2013) has contended, a core issue of developing English as the language of science is "unburdening English of its association with any specific country and treating it as a skill that anyone can learn" (p. 179). English should be like chemistry or algebra—a skill that any scientist will need to operate academically. 
The results reinforce the need to think about the English classrooms in China and elsewhere as ecosystems, within which we need to think about the English environment as a whole. The English classroom is a large ecosystem. The physical, teaching, learning and motivational sub-ecosystems are interdependent and mutually interacting. In order to create a favorable foreign language learning environment for learners, we should expand our understanding of the classroom environment from an ecological perspective and highlight the interaction between the teacher, students and the classroom settings in the whole classroom ecosystem.

An ideal learning environment is essential for the quality of classroom teaching. As Williams and Burden (1997) have argued, "learning occurs within a variety of often overlapping contexts, some of which are more conducive to the process of cognitive, affective, moral and social development than others" (p. 188). Therefore, it is clear that understanding the affordances and constraints around the classroom environment on different EFL learners is important in language teaching. This study only distinguishes English majors and non-English majors; future research should involve learners from diverse majors.

\section{Acknowledgements}

I am deeply indebted to Ian Westbury of the University of Illinois at Urbana-Champaign for his insightful guidance on this research. I would also like to thank Lisa Chason for her valuable feedback and Xing Mei for data collection.

\section{References}

Bronfenbrenner, U. (1976). The experimental ecology of education. Educational Researcher, 5(9), 5-15. http://dx.doi.org/10.2307/1174755

Brown, H. D. (2002). English language teaching in the 'post-method' era: toward better diagnosis, treatment, and assessment. In J. C. Richards, \& W. A. Renandya (Eds.), Methodology in language teaching: An anthology of current practice (pp. 9-18). New York: Cambridge University Press. http://dx.doi.org/10.1017/CBO9780511667190.003

Brown, H. D. (2007). Teaching by principles: An interactive approach to language pedagogy (3rd ed.). White Plains, NY: Pearson Education.

Dollahite, N. E., \& Haun, J. (2012). Sourcework: Academic writing from sources. Boston: Heinle/Cengage Learning.

Dornyei, Z. (2014). Motivation in second language learning. In M. Celce-Murcia, D. M. Brinton, \& M. A. Snow (Eds.), Teaching English as a second or foreign language (4th ed.) (pp. 518-531). Boston: National Geographic Learning.

Doyle, W. (1977). Paradigms for research on teacher effectiveness. Review of Research in Education, 5, 163-198. http://dx.doi.org/10.2307/1167174

Doyle, W. (2006). Ecological approaches to classroom management. In C. M. Evertson, \& C. S. Weinstein (Eds.), Handbook of classroom management: Research, practice, and contemporary issues (pp. 97-126). Mahwah, N.J.: Lawrence Erlbaum Associates.

Fan, G. R. (2000). Educational ecology. Beijing: People's Education Press.

Harmer, J. (2000). How to teach English. Beijing: Foreign Language Teaching and Research Press.

Hinkel, E. (2014). Culture and pragmatics in language teaching and learning. In M. Celce-Murcia, D. M. Brinton, \& M. A. Snow (Eds.), Teaching English as a second or foreign language (4th ed.) (pp. 394-408). Boston: National Geographic Learning.

Kinsella, K. (1995). Understanding and empowering diverse learners in ESL classrooms. In J. M. Reid (Ed.), Learning styles in the ESL/EFL classroom (pp. 170-194). New York: Heinle \& Heinle Publishers.

Ministry of Education in China. (2007). College English curriculum requirements. Shanghai: Shanghai Foreign Language Education Press.

Montgomery, S. L. (2013). Does science need a global language? English and the future of research. Chicago: University of Chicago Press.

Nunan, D. (2001). Second language teaching and learning. Beijing: Foreign Language Teaching and Research Press.

Peng, J. E. (2012). Towards an ecological understanding of willingness to communicate in EFL classrooms in China. System, 40(2), 203-213. http://dx.doi.org/10.1016/j.system.2012.02.002 
Pielstick, N. L. (1988) Assessing the learning environment. School Psychology International, 9(2), 111-122. http://dx.doi.org/10.1177/0143034388092005

Richards, J. C., \& Rodgers, T. S. (2001). Approaches and methods in language teaching (2nd ed.). Cambridge: Cambridge University Press.

Weger, H. D. (2013). Examining English language learning motivation of adult international learners studying abroad in the US. RELC Journal, 44(1), 87-101. http://dx.doi.org/10.1177/0033688212473272

Williams, M., \& Burden, R. L. (1997). Psychology for language teacher: A social constructivist approach. Cambridge: Cambridge University Press.

$\mathrm{Wu}, \mathrm{X}$. Y. (2003). Intrinsic motivation and young language learners: the impact of the classroom environment. System, 31(4), 501-517. http://dx.doi.org/10.1016/j.system.2003.04.001

\section{Notes}

Note 1. In addition, TEM 8 (for English majors) contains items regarding news broadcasting and general knowledge of English-speaking countries. However, CET 4 and CET 6 (for non-English majors) do not contain such cultural elements. So culture learning is test-relevant for English majors, but not for non-majors.

\section{Copyrights}

Copyright for this article is retained by the author(s), with first publication rights granted to the journal.

This is an open-access article distributed under the terms and conditions of the Creative Commons Attribution license (http://creativecommons.org/licenses/by/3.0/). 